\title{
ASSOCIATION OF HIGHLY SENSITIVE CRP AND THE NUMBER OF CRITERIA MET IN METABOLIC SYNDROME PATIENTS
}

Natarajan Kandaswamy¹, Vijayanand Radhakrishnan², Thilakavathy Rajendran³, Ragavendra Chandanamuthu4, Ayyappan Ganesan5, Ravichandran Narayannan6, Raja Krishnaraj7, Dhanraj Subramanian ${ }^{8}$

\begin{abstract}
${ }^{1}$ Associate Professor, Department of Medicine, Government Stanley Medical College. ${ }^{2}$ Assistant Professor, Department of Medicine, Government Stanley Medical College. ${ }^{3}$ Assistant Professor, Department of Medicine, Government Stanley Medical College. ${ }^{4}$ Postgraduate, Department of Medicine, Government Stanley Medical College. ${ }^{5}$ Postgraduate, Department of Medicine, Government Stanley Medical College. ${ }^{6}$ Assistant Professor, Department of Medicine, Government Stanley Medical College. ${ }^{7}$ Assistant Professor, Department of Medicine, Government Stanley Medical College. ${ }^{8}$ Assistant Professor, Department of Medicine, Government Stanley Medical College.
\end{abstract}

\section{ABSTRACT}

\section{BACKGROUND}

Metabolic syndrome is known to predispose to atherosclerosis. C-reactive protein, a marker of systemic inflammation is significantly associated with the atherosclerotic process.(1)

\section{METHODS}

We prospectively studied the relationship between high-sensitivity C-reactive protein (hs-CRP) with various components of metabolic syndrome in 50 patients with metabolic syndrome at our tertiary care centre in Chennai, Tamil Nadu.

\section{RESULTS}

50 patients diagnosed with metabolic syndrome were studied. There were 21 males and 29 females. In our analysis, hs-CRP was found to be significantly increased in patients with diabetes mellitus $(\mathrm{p}<0.023)$ with increase in duration of diabetes ( $\mathrm{p}<0.0446)$, those whose diabetes was not controlled $(\mathrm{p}<0.0365)$ and those with abnormal waist circumference $(\mathrm{p}<0.0019)$. There was no significant association between hs-CRP and high triglycerides, hypertension, reduced high density lipoprotein cholesterol. HS-CRP increased significantly with increasing number of components of metabolic syndrome $(p<0.0001)$. HS-CRP was found to be elevated in about two-third (68\%) of patients with metabolic syndrome.

\section{CONCLUSIONS}

Measurement of hs-CRP can be used as a surrogate marker of chronic inflammation in patients with metabolic syndrome and has a positive correlation with the number of components met in metabolic syndrome patients.

\section{KEYWORDS}

Metabolic Syndrome, CRP, No. of Criteria Met, India, Diabetes.

HOW TO CITE THIS ARTICLE: Kandaswamy N, Radhakrishnan V, Rajendran T, et al. Association of highly sensitive CRP and the number of criteria met in metabolic syndrome patients. J. Evolution Med. Dent. Sci. 2016;5(64):4520-4523, DOI: $10.14260 /$ jemds/2016/1032

\section{INTRODUCTION}

Metabolic syndrome is composed of a constellation of disorders like hypertension, dyslipidaemia, visceral obesity and hyperglycaemia. The occurrence of these disorders together substantially increases the risk of cardiovascular diseases. In both developing as well as developed countries, the epidemic of obesity and diabetes mellitus is in ever increasing trend, hence increasing the prevalence of metabolic syndrome worldwide. ${ }^{[1]}$

Metabolic syndrome is a pro-inflammatory condition. The risk of cardiovascular diseases in people with metabolic can be predicted by measurement of markers of inflammation like high sensitive C-reactive protein. Several studies have shown that several components of metabolic syndrome are

Financial or Other, Competing Interest: None.

Submission 28-05-2016, Peer Review 20-07-2016,

Acceptance 26-07-2016, Published 09-08-2016.

Corresponding Author:

Vijayanand Radhakrishnan

\#20, Corporation Lines,

North T Nagar,

Chennai 17.

E-mail: rva711@yahoo.co.in

DOI: $10.14260 /$ jemds/2016/1032 associated with CRP. The elevated CRP levels are caused due to the production of cytokines by adipocytes. Several cytokines are secreted by the adipose tissue, among which is interleukin 6. Interleukin 6 causes upregulation of CRP production by the liver. Thus, additional information about prognosis of cardiovascular risk in metabolic syndrome patients can be obtained by measuring the CRP levels. From India very little has been documented about this topic. The objective of the present study is to find the association between hs-CRP and components of metabolic syndrome. ${ }^{[2]}$

\section{METHODOLOGY}

Patients aged above 20 years presenting to the Medicine OutPatient Service and those admitted to the medical wards at Stanley Medical College Hospital, Chennai were included in the present study. The data were recorded from each subject with an in-person interview by administering a specific questionnaire. The components of metabolic syndrome were defined according to the modified National Cholesterol Education Program Adult Treatment Panel III (NCEP-ATP III) criteria considering abdominal obesity as per World Health Organization (WHO) guidelines for South Asians. 
Waist circumference was measured using a non-elastic measuring tape at the highest level of iliac crest with the patient standing with feet 1 foot apart. Systolic and diastolic blood pressure was measured by sphygmomanometer. Individuals reporting a history of hypertension and current antihypertensive medication use were defined as having hypertension regardless of the blood pressure values measured at the time of evaluation. Diabetes mellitus was diagnosed as per the American Diabetic Association (ADA) diagnostic criteria and/or concomitant anti-diabetic treatment, regardless of the measured glucose values. ${ }^{[3]}$

In all the patients, a peripheral venous blood sample was to be drawn in the morning after 8 - 10 hours of fasting, to measure venous plasma glucose, serum total cholesterol, serum high density lipoprotein (HDL) cholesterol, and serum triglyceride levels. Serum glucose was to be measured by the glucose oxidase method; plasma triglycerides, total cholesterol and HDL-cholesterol were to be measured by enzymatic colorimetric assay using autoanalyser. Serum hsCRP levels were to be determined by immune-turbidimetric assay using with dedicated reagents. We used CRP cut-off values of $3.0 \mathrm{mg} / \mathrm{l}$, as recommended by the Centres for Disease Control and the American Heart Association. The study period is from January 2015 to May 2015.[4]

The full protocol along with draft questionnaire and Informed consent was kept in Institutional Ethical Committee and approval was obtained. Consent form will be written in both English and Tamil and consent was obtained from the participant, confidentiality was maintained.

\section{AIMS AND OBJECTIVES OF STUDY}

To test association between hs-CRP and number of individual components of metabolic syndrome.

\section{OPERATIONAL DEFINITIONS \\ Case Definition}

Metabolic syndrome was defined as the presence of at least 3 of the following criterias:

The cut-off point of waist circumference is $\geq 90 \mathrm{~cm}$ in men and $\geq 80 \mathrm{~cm}$ in women according to the recommendation by the World Health Organization (WHO) guidelines for South Asians.

- Triglycerides $\geq 150 \mathrm{mg} / \mathrm{dL}$ or treatment for hypertriglyceridemia.

- HDL-C $<40 \mathrm{mg} / \mathrm{dL}$ in men or $<50 \mathrm{mg} / \mathrm{mL}$ in women or treatment for low HDL-C.

- Blood pressure $\geq 130 / 85 \mathrm{mmHg}$ or treatment for hypertension.

- Fasting glucose $\geq 100 \mathrm{mg} / \mathrm{dL}$ or treatment for hyperglycaemia.

High Sensitivity CRP (hs-CRP) levels were measured by enzyme-linked immunosorbent assay and defined as high when $>3 \mathrm{mg} / \mathrm{L}$.

\section{PATIENT SELECTION}

\section{Inclusion Criteria}

1. Metabolic syndrome diagnosed patients according to the NCEP ATP 111 criteria considering abdominal obesity as per World Health Organization (WHO) guidelines for South Asians.

2. Age - more than 20 years.

\section{Exclusion Criteria}

1. Patients taking statins, aspirin, thiazolidinediones.

2. Patients with acute infections.

3. Patients with chronic inflammatory conditions like inflammatory bowel disease, osteoarthritis, rheumatoid arthritis, gout, bronchial asthma and chronic hepatitis.

4. Patients with acute myocardial infarction, cerebral infarction.

5. Patients with chronic kidney disease.

\section{RESULTS}

The patients were divided into two groups - hs-CRP negative Group and hs-CRP positive Group. Descriptive statistics was done for all data and were reported in terms of mean values and percentages. Suitable statistical tests of comparison were done. Continuous variables were analysed with the unpaired ' $\mathrm{T}$ ' test. Categorical variables were analysed with Fisher Exact Test. Statistical significance was taken as $P<0.05$. The data was analysed using SPSS version 16 and Microsoft Excel 2007.

Sample size was determined based on the study "Highly sensitive C-reactive protein in metabolic syndrome" authored by Sudha Vidyasagar et al and published in JIACM 2013;14(34):230-4. In this study the onunivariate analysis, hs-CRP was found to be significantly increased in patients with diabetes mellitus (86\%) $(\mathrm{p}<0.021)$.

The confidence level is estimated at $95 \%$ with a $Z$ value of 1.96 and the confidence interval or margin of error is estimated at $+/-10$. Assuming $\mathrm{p}=86 \%$ and $\mathrm{q}=14 \%$.

$$
\begin{aligned}
& \mathrm{n}=\mathrm{p} \times \mathrm{q} \times[\mathrm{z} / \mathrm{e}] .^{2} \\
& \mathrm{n}=86 \times 14 \times[1.96 / 12] .^{2} \\
& \mathrm{n}=46.25
\end{aligned}
$$

Therefore, 46 is the minimum sample size required for the study.

In our study, we have taken 50 as the sample size

- $\mathrm{n}=14$ in hs-CRP negative Group.

- $\mathrm{n}=36$ in hs-CRP positive Group.

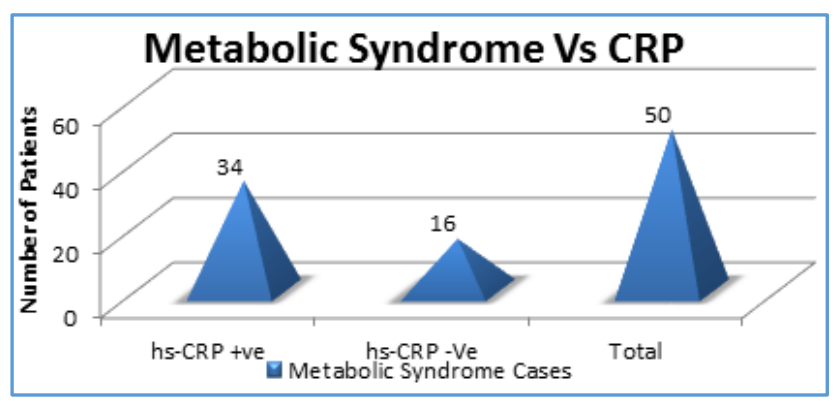

\begin{tabular}{|c|c|c|}
\hline $\begin{array}{c}\text { Metabolic Syndrome } \\
\text { vs. CRP }\end{array}$ & $\begin{array}{c}\text { Metabolic } \\
\text { Syndrome Cases }\end{array}$ & $\begin{array}{c}\text { Percent } \\
\text { Age }\end{array}$ \\
\hline hs-CRP +ve & 34 & 68 \\
\hline hs-CRP -Ve & 16 & 32 \\
\hline Total & $\mathbf{5 0}$ & $\mathbf{1 0 0}$ \\
\hline
\end{tabular}

About 34 patients had tested positive for hs-CRP, in total 50 metabolic syndrome patients. This shows us that there is a $68 \%$ association of CRP with metabolic syndrome. 


\section{Metabolic Syndrome - Number of Criteria met}

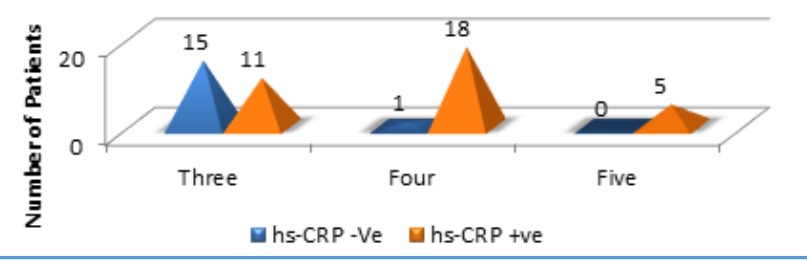

\begin{tabular}{|c|c|c|c|c|}
\hline $\begin{array}{c}\text { Metabolic } \\
\text { Syndrome - } \\
\text { No. of } \\
\text { Criteria Met }\end{array}$ & $\begin{array}{c}\text { hs-CRP } \\
\text {-Ve }\end{array}$ & $\mathbf{\%}$ & $\begin{array}{c}\text { hs- } \\
\text { CRP +ve }\end{array}$ & $\mathbf{\%}$ \\
\hline Three & 15 & 93.75 & 11 & 32.35 \\
\hline Four & 1 & 6.25 & 18 & 52.94 \\
\hline Five & 0 & 0.00 & 5 & 14.71 \\
\hline Total & $\mathbf{1 6}$ & $\mathbf{1 0 0}$ & $\mathbf{3 4}$ & $\mathbf{1 0 0}$ \\
\hline \multicolumn{4}{|c|}{$\begin{array}{c}\text { P value } \\
\text { Fisher's Exact Test }\end{array}$} \\
\hline
\end{tabular}

There is a true difference among study groups in relation to number of metabolic syndrome criteria met and this difference is considered to be statistically significant since $p$ $<0.05$ as per Fisher's exact test. In simple terms, most of the hs-CRP -ve Group patients had three metabolic syndrome criteria met $(\mathrm{n}=15,93.75 \%)$. In the hs-CRP +ve Group patients majority had four metabolic syndrome criterias met, did not exercise regularly $(n=18,52.94 \%)$. This difference in metabolic syndrome criteria met among the study groups is expressed with a $\mathrm{p}$ value of 0.0001 . Three metabolic syndrome criteria met was meaningfully more in hs-CRP -ve Group compared to hs-CRP +ve Group by 61.40 percentage points. Four metabolic syndrome criteria met was meaningfully less in hs-CRP -ve Group compared to hs-CRP +ve Group by 46.69 percentage points. Five metabolic syndrome criteria met was meaningfully less in hs-CRP -ve Group compared to hs-CRP +ve Group by 14.71 percentage points. This significant difference of 2.90 times increase in incidence of three metabolic syndrome criteria met, $88 \%$ decrease in incidence of four metabolic syndrome criteria met in hs-CRP -ve Group compared to hs-CRP +ve Group, is true and has not occurred by chance. In this study, we can safely conclude that increase in number of metabolic syndrome criteria met in metabolic syndrome patient's results in higher hs-CRP positivity and decrease in number of metabolic syndrome criteria met in metabolic syndrome patient's results in higher hs-CRP negativity.[5]

\section{DISCUSSION}

People with metabolic syndrome are predisposed to develop heart diseases and diabetes. The main pathogenesis of metabolic syndrome is insulin resistance. CRP levels tend to increase with increase in number of components of metabolic syndrome. CRP levels tends to predict the risk of non-diabetic metabolic syndrome patients developing diabetes. It also predicts the risk of developing coronary heart diseases in people with metabolic syndrome. CRP has now increasingly become a part of the process of defining metabolic syndrome.

\section{METHODS TO LOWER CRP LEVELS}

The best way to lower CRP levels is to undergo lifestyle modifications. These include exercise, smoking cessation, blood pressure control and diet. Thus, the most important role of measuring CRP levels is to identify people with high risk even with low cholesterol levels and to motivate them towards heart healthy interventions.

\section{Effect of Therapy}

Undertaking certain modifications in diet and taking a number of drugs to treat cardiovascular diseases can reduce serum CRP levels.

\section{STATINS}

\section{Effect on CRP}

In patients with hyperlipidaemia, multiple statins decrease the serum CRP levels significantly. This effect is found to be independent of the decrease in serum LDL cholesterol levels. The mechanism by which statins reduce the levels of CRP is partly by reducing the expression of IL- 6 and tumour necrosis factor alpha by the monocytes and by direct suppression of transcription of CRP gene. ${ }^{[5]}$

Statin therapy causes reduction of CRP levels both when used for primary prevention and for reduction of serum CRP after an ACS. As early as 14 days after starting statin therapy, serum CRP levels tend to fall. In review of literature of about thirteen controlled trials, it was found out that serum CRP levels are reduced from 13 to 50 percent with statin therapy as compared to placebo therapy and according to five studies comparing different statins it was found out that there was no advantage of one statin over another in reducing the CRP levels. According to the phase $\mathrm{Z}$ of the $\mathrm{A}$ to $\mathrm{Z}$ trial, a modestly greater reduction in CRP levels was found with intensive statin therapy.

\section{Reduction in Coronary Risk}

Several studies have correlated that elevated CRP levels is associated with increased cardiovascular risk. Statins because of their anti-inflammatory action are postulated to reduce the risk of cardiovascular events. Several studies have been conducted to support this concept.

In studies conducted in patients undergoing PCI, it was found out that statin therapy benefit was seen in those who had higher quartile of CRP levels. According to the AFCAPS/TEXCAPS trial of primary prevention, it was found out that CRP levels are reduced by almost 15 percent by using lovastatin. Reduction in coronary events on using statin was found not only in those with deranged lipid parameters, but also who had normal LDL-HDL ratio with elevated CRP levels. [6]

According to phase $\mathrm{Z}$ of $\mathrm{A}$ to $\mathrm{Z}$ trial, it was shown that lower level of hs-CRP at the end of thirty days and at the end of four months after an acute coronary syndrome were associated with increased long-term survival and those patients who received aggressive statin therapy were found to have more likelihood of achieving lower hs-CRP levels.

A higher two-year mortality was found in patients who at the end of 30 days had an hs-CRP levels of greater than 3 $\mathrm{mg} / \mathrm{L}$ when compared to those who had an hs-CRP levels less than $1 \mathrm{mg} / \mathrm{L}$. It was found out that patients who were given intensive statin therapy, there was more likelihood of 
achieving lower values less than $1 \mathrm{mg} / \mathrm{L}$ at the end of 30 days and 4 months.

According to PROVE IT - TIMI 22 trial in which about 4162 patients with ACS were randomly assigned to either 80 $\mathrm{mg} /$ day of atorvastatin or $40 \mathrm{mg} / \mathrm{kg}$ of pravastatin. It was found out that at the end of thirty days, significant reductions was achieved in levels of CRP in both groups and a linear relationship was found to exist between the levels of CRP levels attained after statin therapy, the risk of developing recurrent myocardial infarction or coronary deaths.

According to REVERSAL trial in which about 502 patients were studied, intravascular ultrasonography was used to monitor the progression of atherosclerosis in patients with angiographic coronary disease. It was found out that those patients in the group who received statins had a significantly slower progression of atherosclerosis and maximum regression was seen in those who had the greatest fall in the levels of CRP.[6]

According to JUPITER trial, patients with LDL value less than $130 \mathrm{mg} / \mathrm{dL}$ and CRP level higher than $2 \mathrm{mg} / \mathrm{L}$ were assigned into two groups, ones which received rosuvastatin $20 \mathrm{mg}$ daily and the other which received placebo. It was found out that the treated group had better clinical outcomes.

\section{Dietary Modification}

Studies have shown that certain dietary modifications are found to lower serum CRP levels. It was found out that the diet rich in viscous fibre, plant sterols, soy protein and nuts with low levels of calorie and fat restriction were found to reduce serum CRP levels and addition of statin to the diet has been found to drastically decrease the levels of serum CRP.

\section{CONCLUSIONS}

Measurement of hs-CRP can be used as a surrogate marker of chronic inflammation in patients with metabolic syndrome and has a positive correlation with the number of components met in metabolic syndrome patients.

\section{REFERENCES}

1. Nash, David T. C-reactive protein: a promising new marker of cardiovascular risk. Consultant 2005;45(4):453-7.

2. Kamath DY, Xavier D, Sigamani A, et al. High sensitivity C-reactive protein (hs-CRP) \& cardiovascular disease: an Indian perspective. Indian J Med Res 142, 2015:261-8. DOI:10.4103/09715916.166582 .

3. Vidyasagar S, Razak UKA, Prashanth CK, et al. Highly sensitive C-reactive protein in metabolic syndrome. Journal, Indian Academy of Clinical Medicine 2013;14(3-4):230-4.

4. Huffman FG, Gomez GP, Zarini GG. Metabolic syndrome and high-sensitivity c-reactive protein in cubans. Ethnicity \& Disease 2009;19(2):115-20.

5. Engelsen CD, Koekkoek PS, Gorter KS, et al. Highsensitivity C-reactive protein to detect metabolic syndrome in a centrally obese population: a crosssectional analysis. Cardiovascular Diabetology 2012;11:25.

6. Cruz LL, Cardoso LD, Pala D, et al. Metabolic syndrome components can predict C-reactive protein concentration in adolescents. Nutr Hosp 2013;28(5):1580-6. 